\title{
Interactive comment on "The challenges of an in situ validation of a non-equilibrium model of soil heat and moisture dynamics during fires" by William J. Massman
}

\section{William Massman}

wmassman@fs.fed.us

Received and published: 7 July 2020

I concur with the referee. I did overlook clearly stating that the bulk density of the soil is assumed to be uniform with depth. The two lines following Equation (4) now read:

"where $\eta\left(\mathrm{m}^{3} \mathrm{~m}^{-3}\right)$ is the total soil porosity, assumed to be temporally constant and spatially uniform (note: these assumptions about $\eta$ also apply to the soil's bulk density and particle density as well),..." 